\title{
Production of Pyracantha Polysaccharide-Iron(III) Complex and Its Biologic Activity
}

\author{
Wan-Fen $\mathrm{Li}^{\dagger}{ }^{\dagger}$, Hao-Hai Ma ${ }^{\dagger}$, Shuai Yuan and Xi-Feng Zhang * \\ College of Veterinary Medicine, Qingdao Agricultural University, Qingdao 266109, China; \\ liwfqd1981@163.com (W.-F.L.); mahaohai741@163.com (H.-H.M.); arbeit19960413@163.com (S.Y.) \\ * Correspondence: zhangxf106@qau.edu.cn \\ † These authors contributed equally to this work.
}

Citation: Li, W.-F.; Ma, H.-H.; Yuan, S.; Zhang, X.-F. Production of Pyracantha Polysaccharide-Iron(III) Complex and Its Biologic Activity. Molecules 2021, 26, 1949. https:// doi.org/10.3390/molecules26071949

Academic Editor: M. Gilles Mailhot

Received: 4 March 2021

Accepted: 23 March 2021

Published: 30 March 2021

Publisher's Note: MDPI stays neutral with regard to jurisdictional claims in published maps and institutional affiliations.

Copyright: (c) 2021 by the authors. Licensee MDPI, Basel, Switzerland. This article is an open access article distributed under the terms and conditions of the Creative Commons Attribution (CC BY) license (https:// creativecommons.org/licenses/by/ $4.0 /)$.
Abstract: In this study, the optimum synthetic process of the Pyracantha polysaccharide-iron (PPI) complex was studied via response surface methodology (RSM). Its antioxidant and anti-cancer activities were also investigated. It was demonstrated that the optimal conditions for the synthetic process of the complex were as follows: a pH of 8.9 , a reaction temperature of $70{ }^{\circ} \mathrm{C}$ and a trisodium citrate:polysaccharide ratio of 1:2. PPI were analysis by UV, FTIR, SEM, CD, XRD, TGA and NMR. PPI was able to scavenge the metal ion, ABTS and free radicals of the superoxide anion, demonstrating its potential antioxidant activity. PPI was found to display cytotoxicity to Skov3 cells, as shown by its ability to induce apoptosis and alter gene expression in Skov3 cells. These findings show than PPI may represent a novel antioxidant and chemotherapeutic drug.

Keywords: polysaccharides; polysaccharide iron; response surface optimisation; antioxidant

\section{Introduction}

Polysaccharides are ubiquitous biological macromolecules that are involved in myriad physiological human processes. These molecules have been documented to enhance the body's immunity, prevent tumours, and possess antiviral properties. Modern day formulations of polysaccharides in combination with metals and non-metals have been shown to possess good functional qualities [1]. Iron is an essential trace element in the human body and participates in several enzymatic reactions in the body, with its most well-known role being oxygen transportation as well as the maintenance of cellular metabolism [2]. A polysaccharide iron complex can be used as a supplement that has very stable properties. Valent iron complexes that enter the body produce free radicals, which contribute to cell membrane damage [3]. Oral consumption of iron complexes also leads to a host of side effects, such as nausea and vomiting [4]. Polysaccharide iron complexes are usually complexes of ferric ions [5,6]. These compounds have a relatively high iron concentration and can be soluble and non-toxic at physiological $\mathrm{pH}$ values, making them an efficacious iron supplement in the body [7].

Many studies have shown that the polysaccharide iron complex possesses high stability, water solubility and a good absorption rate [8-10]. It also has a safer adverse event profile compared to ferrous sulphate. Given these excellent properties, the polysaccharide iron complex has gained recognition as a potential treatment for anaemia. Chemical synthesis and simulated biomineralisation are the main methods for the preparation of polysaccharide iron complexes, with the former method being more common. The polysaccharide iron complex is a chelation consisting of polysaccharides and iron that does not cause gastrointestinal discomfort, as the ferric iron is bound and not in its free state. In the body, ferric iron is absorbed and reduced to ferrous ion. Polysaccharide chelated iron exists mostly in a ferric state. The polysaccharide is primarily extracted from plants and has immunomodulatory effects. The Pyracantha fortuneana fruit is a high-quality medicinal and 
edible natural plant resource that contains several active ingredients. It is rich in carbohydrates and the total soluble sugar content of the flesh of the fruit has been reported to be between 10.59-13.40\% [11]. Polysaccharides derived from the Pyracantha fortuneana fruit are promising compounds to be used in the formulation of polysaccharide iron complexes. We have completed the extraction and structural characterization of polysaccharides of Pyracantha fortuneana (PSPF) [12].

In this study, response surface methodology (RSM) was used to study the preparation of PPI, and the antioxidant effect of the Pyracantha polysaccharide-iron(III) complex was also studied. Human ovarian carcinoma cells (Skov3) was used as a model cell to investigate the anti-cancer activity of this compound.

\section{Results and Discussion}

\subsection{Establishment of a Standard Curve for Iron}

Based on the absorbance of different concentration gradients at $510 \mathrm{~nm}$, the regression equation is given as the following equation: $y=0.0982 x+0.0041\left(R^{2}=0.999\right)$. There was a good linear relationship from $0.4-2.8 \mu \mathrm{g} / \mathrm{mL}$.

\subsection{Response Surface Optimization of PPI Complexsynthesis Conditions}

Response surfaces were plotted using Design Expert software [13]. As shown in Figure 1, response surface plots and the respective contour plots demonstrated the effects of two factors and were used to obtain the optimum conditions for the production of PPI. The interactions amongst the factors in the response surface can be intuitively shown by the degree of contour density in the contour map and the steepness of the response surface map in Figure 1. Figure $1 \mathrm{~A}, \mathrm{~B}$ represents the effects of different $\mathrm{pH}\left(\mathrm{X}_{1}\right)$ and different extraction temperatures $\left(\mathrm{X}_{2}\right)$ on complex synthesis at a given amount of catalyst. It shows that the 3-D plot and the contour plot described the effect of $\mathrm{pH}$ surface as relatively steep with a more intensive contour.

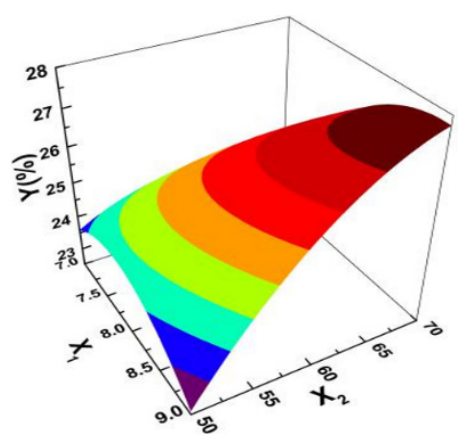

(A)

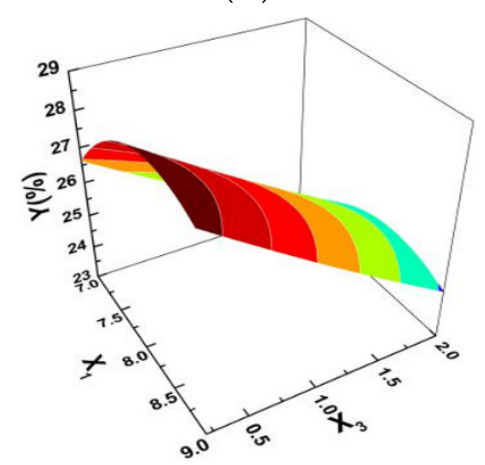

(C)

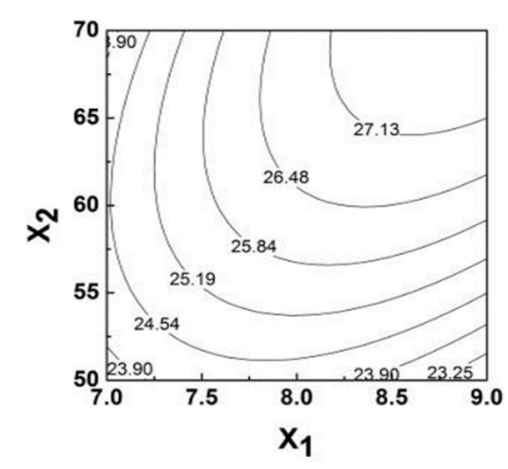

(B)

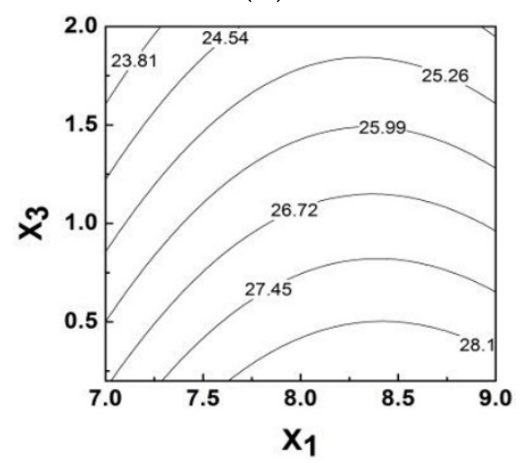

(D)

Figure 1. Cont. 


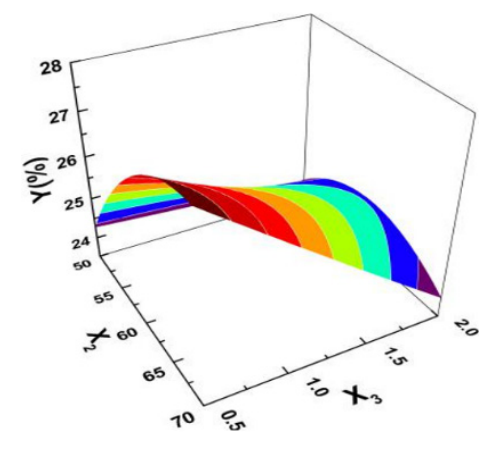

(E)

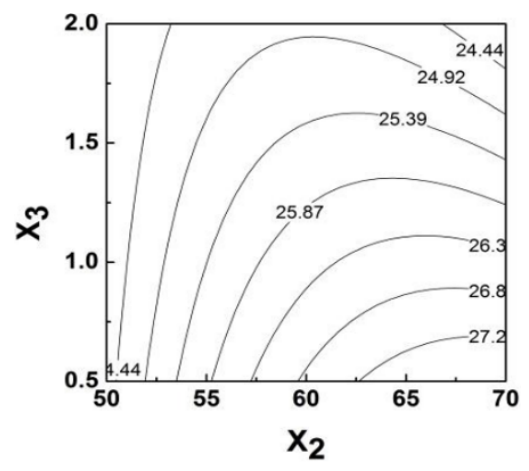

(F)

Figure 1. Response surface plots showing the effects of variables on the yield of PPI. (A,B) Plots of the effect of $\mathrm{pH}$, temperature and their reciprocal interactions on the iron content (\%). (C,D) Plots of the effect of $\mathrm{pH}$, ratio of trisodium citrate to polysaccharide and their reciprocal interactions on the iron content (\%). (E,F) Plots of the effect of temperature, ratio of trisodium citrate to polysaccharide and their reciprocal interactions on the iron content (\%).

Comparatively, the contour plot for effect of reaction temperature of the surface was smooth with relatively sparse contours, indicating that $\mathrm{pH}$ levels had a more significant effect on PPI synthesis. Figure 1C,D shows the 3-D plot and the contour plot at ratio of catalyst to Pyracantha fortuneana polysaccharides (PSPF) and $\mathrm{pH}$. The effect of catalyst surface is relatively steep, dense and possesses obvious contours while the contour plot of the $\mathrm{pH}$ effect is relatively smooth with sparse contours, indicating that the catalysts used has a more significant effect on PPI synthesis. The 3-D plot and the contour plot based on independent variable ratio of catalyst to polysaccharides and reaction temperature are shown in Figure 1E,F. The contour plot of the effect of the catalyst surface is relatively steep, with more intensive contours, whereas that of the effect of reaction temperature has relatively smooth sparse contours, also indicating the more significant effect of catalysts on PPI synthesis. As shown in Figure 1, the highest point in the graph is also the centre point of the smallest ellipse in the contour line [14]. As shown in the figure above, the contour diagram of polysaccharide iron shows strong interactions amongst the various factors. This conclusion is consistent with the ANOVA results in Table 1.

Table 1. Analysis of variance of the experimental results of the BBD (*** $p<0.001)$.

\begin{tabular}{cccccc}
\hline Source & $\begin{array}{c}\text { Sum of } \\
\text { Squares }\end{array}$ & $\begin{array}{c}\text { Degree of } \\
\text { Freedom }\end{array}$ & $\begin{array}{c}\text { Mean } \\
\text { Square }\end{array}$ & F Value & $p$ Value \\
\hline Model & 60.38 & 9 & 6.710 & 89.09 & $<0.0001^{* * *}$ \\
$\mathrm{X}_{1}$ & 4.96 & 1 & 4.961 & 65.88 & $<0.0001^{* * *}$ \\
$\mathrm{X}_{2}$ & 13.65 & 1 & 13.650 & 181.26 & $<0.0001^{* * *}$ \\
$\mathrm{X}_{3}$ & 19.75 & 1 & 19.750 & 262.25 & $<0.0001^{* * *}$ \\
$\mathrm{X}_{1} \times \mathrm{X}_{2}$ & 6.55 & 1 & 6.550 & 87.02 & $<0.0001^{* * *}$ \\
$\mathrm{X}_{1} \times \mathrm{X}_{3}$ & 0.06 & 1 & 0.058 & 0.76 & $0.4108^{* * *}$ \\
$\mathrm{X}_{2} \times \mathrm{X}_{3}$ & 6.79 & 1 & 6.790 & 90.11 & $<0.0001^{* * *}$ \\
$\mathrm{X}_{1}{ }^{2}$ & 4.98 & 1 & 4.980 & 66.15 & $<0.0001^{* * *}$ \\
$\mathrm{X}_{2}{ }^{2}$ & 3.19 & 1 & 3.190 & 42.34 & $<0.0003^{* * *}$ \\
$\mathrm{X}_{3}{ }^{*}$ & 0.02 & 1 & 0.015 & 0.20 & 0.6685 \\
Residual & 0.53 & 7 & 0.075 & & \\
Lack of Fit & 0.27 & 3 & 0.091 & 1.43 & 0.3586 \\
Pure Error & 0.25 & 4 & 0.064 & & \\
Cor Total & 60.91 & 16 & & & \\
$\mathrm{R}^{2}=0.99$ & $\mathrm{R}^{2}$ Adj $=0.98$ & $\mathrm{R}^{2}$ pred $=0.92$ & Adeq Precisior $=33.86$ & \\
\hline
\end{tabular}

Through the response surface software, the optimal reaction conditions for the production of PPI were $70{ }^{\circ} \mathrm{C} \mathrm{pH} 8.9$ and ratio of catalyst to polysaccharide 0.5 . Under the optimal conditions, we were able to achieve an iron content of PPI of $30.76 \%(n=5)$, close 
to the predicted iron content $30.81 \%$. The model was proven to be valid and can be used as an established protocol for PPI synthesis.

The ANOVA results are demonstrated in Table 1. The significance analysis of experiment results were obtained using the F-value and $p$-value [14]. A large F-value and a small $p$-value indicate a more significant effect on the response variable [15]. According to Table 2, the F-value was 89.09 , and the $p$-value of lack of fit was $<0.0001$, indicating that the lack of fit was not significant. Values of 'Prob. > F', more than 0.0500 indicate not significant model terms. In Table 2, the variables with a significant effect on the yield of PPI were the linear coefficients $\left(X_{1}, X_{2}, X_{3}\right)$, the quadratic term coefficient $\left(X_{1}{ }^{2}, X_{2}^{2}\right)$, and the cross product coefficients $\left(\mathrm{X}_{1 \times 2}, \mathrm{X}_{2} \mathrm{X}_{3}\right)$.

Table 2. Box-Behnken experimental design and the results for the Iron content of polysaccharide iron complex.

\begin{tabular}{ccccc}
\hline \multirow{2}{*}{ Run } & \multicolumn{3}{c}{ Level } & \\
\cline { 2 - 5 } & $\mathbf{X}_{\mathbf{1}}$ & $\mathbf{X}_{\mathbf{2}}$ & $\mathbf{X}_{\mathbf{3}}$ & Fe (\%) \\
\hline 1 & 0 & 0 & 0 & 26.27 \\
2 & 1 & 1 & 0 & 27.90 \\
3 & 0 & 1 & 1 & 23.88 \\
4 & 0 & 1 & -1 & 29.86 \\
5 & 1 & 0 & -1 & 27.55 \\
6 & 1 & 0 & 1 & 24.40 \\
7 & 0 & 0 & 0 & 26.80 \\
8 & -1 & 0 & 1 & 23.35 \\
9 & 0 & 0 & 0 & 26.20 \\
10 & 0 & -1 & 1 & 23.84 \\
11 & 1 & -1 & 0 & 22.76 \\
12 & 0 & -1 & -1 & 24.61 \\
13 & 0 & 0 & 0 & 26.2 \\
14 & -1 & 1 & 0 & 23.48 \\
15 & -1 & -1 & 0 & 23.46 \\
16 & 0 & 0 & 0 & 26.32 \\
17 & -1 & 0 & -1 & 26.02 \\
\hline
\end{tabular}

The model fit was checked against the determination coefficient $\left(R^{2}\right)$ [16]. In this study, the value of $\mathrm{R}^{2}$ Adj $(98.02 \%)$ and the $\mathrm{R}^{2}$ pred of $92.18 \%$ were in reasonable agreement with the $\mathrm{R}^{2}$ Adj of $98.02 \%$. This indicates that the fitted quadratic model accounts for more than $98.02 \%$ of the variations in the experimental data. The coefficient of determination $\mathrm{R}^{2}(99.18 \%)$ shows that the model has a good fitting degree and can be used to analyse and predict the absorbance value of PPI. 'Adeq. Precision' was used to measure the signal to noise ratik. An 'Adeq. Precision' of 33.858 is high enough to indicate that the model is predictive regarding experimental results.

\subsection{Characterisation of PPI}

Figure 2A depicts reactions between PSPF and PPI. The absorption of PPI was in accordance with the previous literature and ranged from $450 \mathrm{~nm}$ to $200 \mathrm{~nm}$, suggesting that the iron core in PPI was Fe-OOH [17]. At the same concentration, compared with indicates that PSPF reacts with iron to form a PSPF, the absorption intensity of PPI in ultraviolet region is obviously increased, which complex without free substance [18]. Figure 2B demonstrates the infrared spectra of PSPF and PPI. The infrared spectra of the two samples are relatively similar, with both displaying strong absorption peaks near $3500-4000 \mathrm{~cm}^{-1}$, which is due to the strong hydrogen bonding of multiple -OH in polysaccharide molecules. They belong to the absorption peaks of light stretching vibrations in the PSPF. As shown in Figure 2B, PPI also possessed another peak at $672.47 \mathrm{~cm}^{-1}$. Taken together, this suggests that the core of the polysaccharide iron complex was a $\beta-\mathrm{FeOOH}$ nucleus, which is consistent with the report of Marshall [19]. 


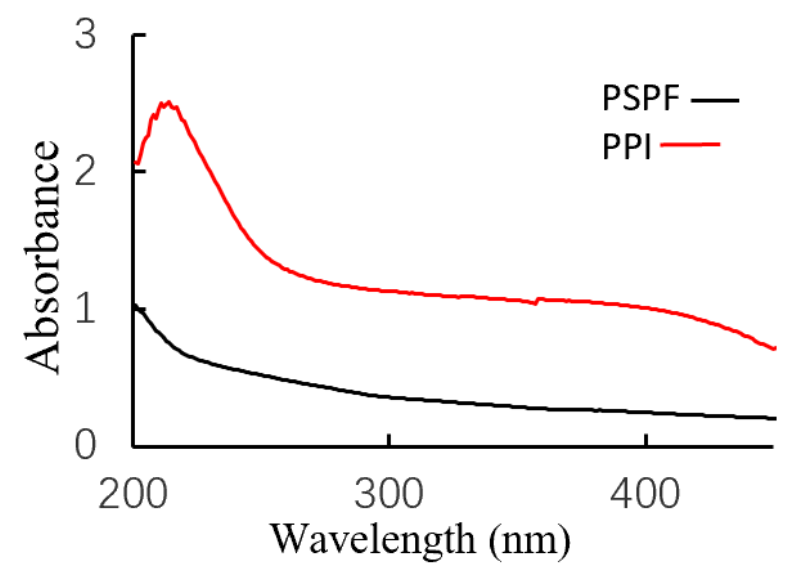

(A)

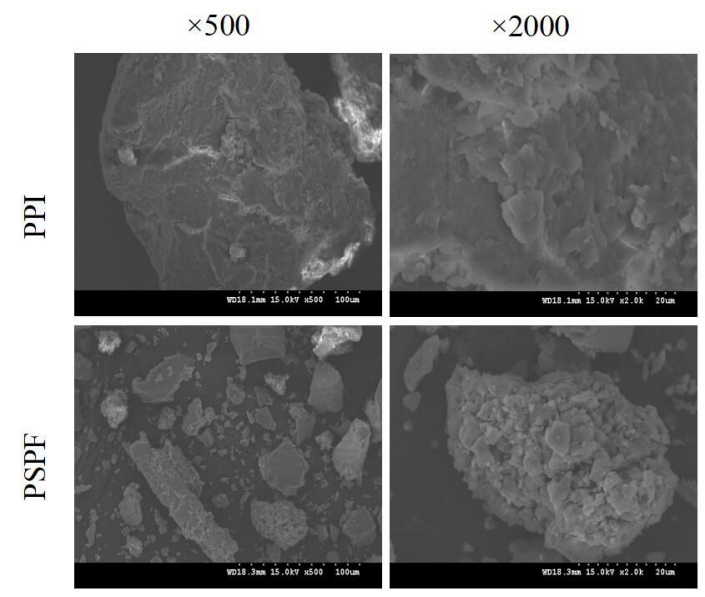

(C)

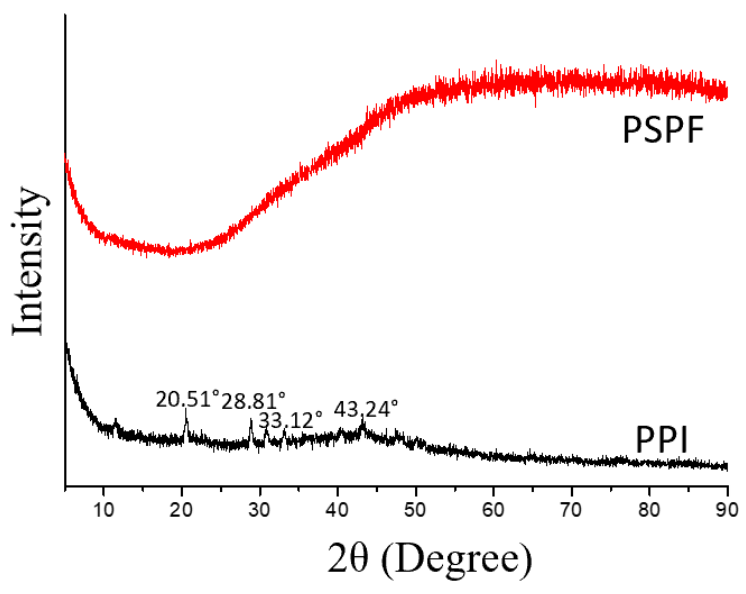

(E)

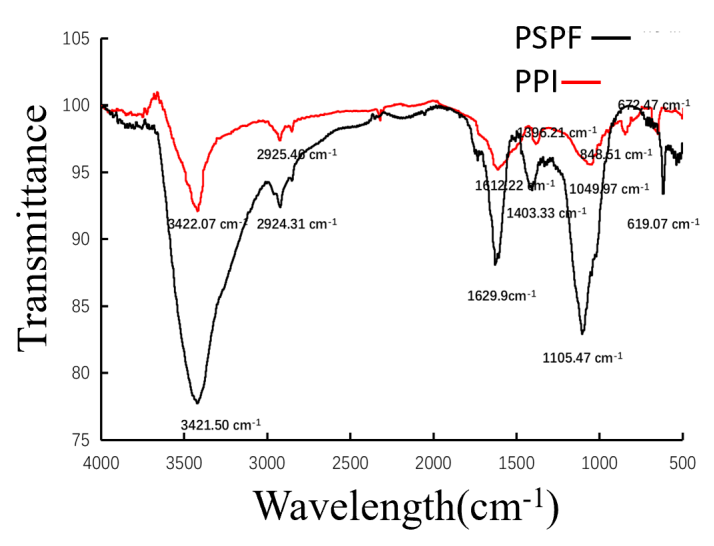

(B)

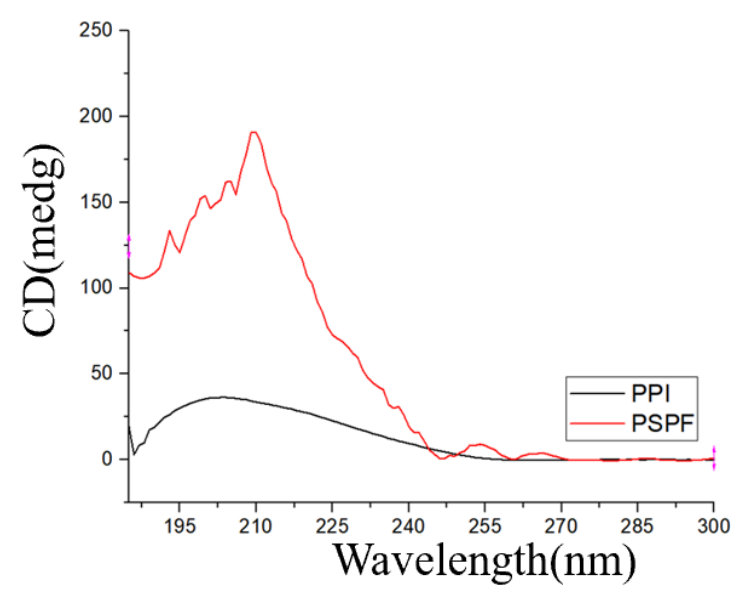

(D)

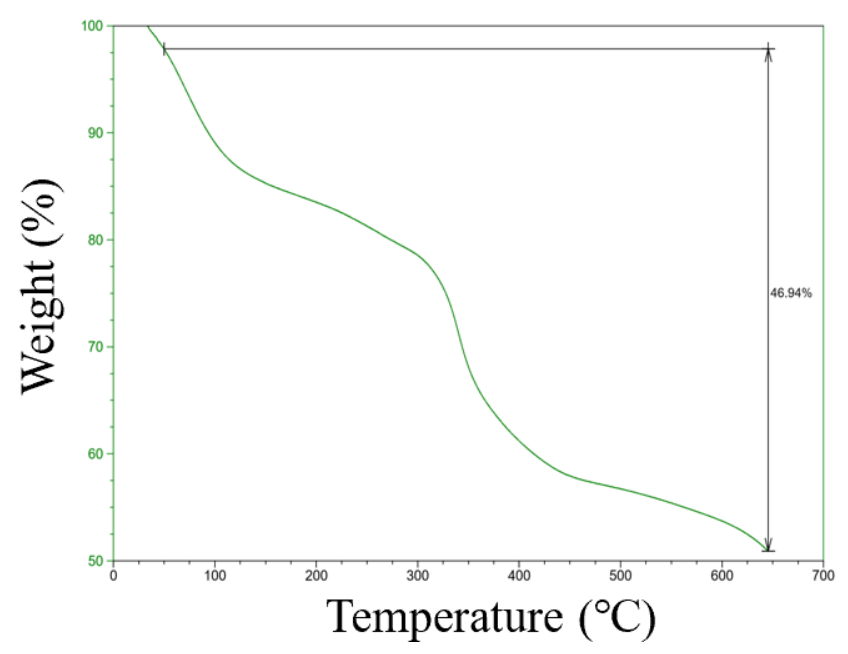

(F)

Figure 2. Cont. 


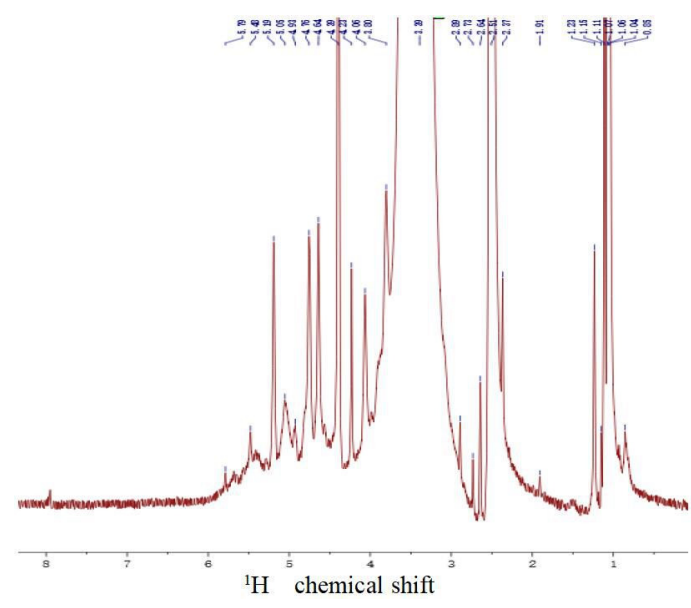

(G)

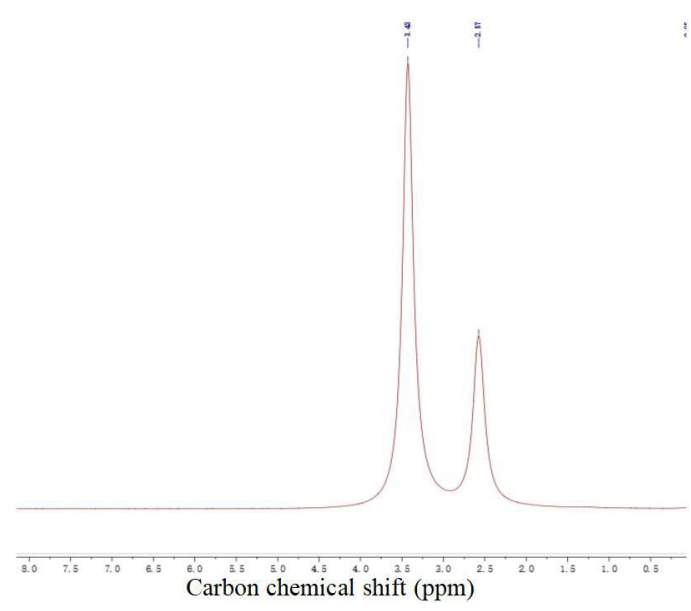

(H)

Figure 2. Analysis of PSPF and PPI (A). UV analysis of PSFP and PPI. (B) FT-IR spectrum of PSFP and PPI. (C) SEM images of the PPI and PSPF. (D).CD spectra of the PPI and PSPF. (E) X-ray diffraction (XRD) pattern of PSPF and PPI. (F) TG curves of PSPF under nitrogen condition. ${ }^{1} \mathrm{H}$ NMR spectra, (G) PSPF, (H) PPI.

The SEM images of PPI and PSPF at different magnifications $(2000 \times$ and $500 \times)$ are illustrated in Figure 2C. The surfaces of PPI and PSPF had obvious variations in size and shape. The image at a low magnification shows that the surface morphology of PSPF was characterised by a small size and homogeneous dispersal. The surface of PPI presents smooth and irregular flaky structure, and the slightly uneven surface of PSPF is more obvious than PPI.

CD was an effective method to investigate the three-dimensional structure of compounds. A new positive Cotton effect appeared at $215 \mathrm{~nm}$ with increasing intensity (Figure 2D), which might suggest that the structural asymmetry in PPI was enhanced, which might be attributed to the charge transfer interaction between iron ions and the carboxyl group in polysaccharide chains [20].

$\mathrm{XRD}$ is an effective method for analysing the microstructure of crystalline materials and some non-crystalline materials. X-ray diffraction patterns of PPI and PSPF are shown in Figure 2E. The XRD pattern of PPI presented strong diffraction peaks at $20-45^{\circ}$ compared to PSPF. The diffraction peaks of PPI were at $20.51^{\circ}, 28.81^{\circ}, 33.12^{\circ}$, and $43.24^{\circ}$. Additionally, the XRD results confirmed that a new compound, PPI, was formed and with a large amount of iron(III) [21].

The thermal gravimetric curve of the PPI is presented in Figure 2F, which shows the degradation pattern of PPI. As shown in Figure 2F, there were three weight loss events for the PPI. The first weight loss of PPI occurred in the temperature range of $25-200{ }^{\circ} \mathrm{C}$ and the loss rate was $18 \%$. The next weight loss of PPI occurred at $200-380{ }^{\circ} \mathrm{C}$ and the loss rate was up to $20 \%$. The third weight loss of PPI occurred at $380-650{ }^{\circ} \mathrm{C}$ and the loss rate was $15 \%$. Therefore, it is relatively stable.

${ }^{1} \mathrm{H}$ NMR spectroscopy were performed for analysis of the structure of PSPF and PPI. The ${ }^{1} \mathrm{HNMR}$ spectrum of PSPF (Figure $2 \mathrm{G}$ ) revealed different linkage patterns at 5.0-4.0 ppm. However, the complete signal pattern of PSPF was missing in the spectrum of PPI (Figure 2H), This might be due to the relatively large, blinded region around high-spin $(S=5 / 2)$ iron(III) centres, which was the same of the reports of the Bertini group [22]. In the metal centre, ligand signals were too broad to be detectable due to shortened relaxation times [23].

\subsection{Antioxidant Activity of PPI}

As shown in Figure 3, PPI exhibited apparent antioxidant activity. The antioxidant activity of PPI through TEAC (on $\mathrm{ABTS}^{+}$radical scavenging activity) is depicted in Figure $3 \mathrm{~A}$. The scavenging activity increased with increasing concentrations of PPI. The maximum 
clearance rate was up to $98.5 \%$, when the concentration of PPI reached $10 \mathrm{mg} / \mathrm{mL}$. Metal chelating activity has long been regarded as a strong antioxidant mechanism given its ability to reduce lipid peroxidation in metal catalysts. The antioxidant activity of PPI through metal ion scavenging activity is shown in Figure 3B. PPI exhibited apparent binding capacity in a concentration-dependent manner. The maximum clearance rate was $63 \%$, when the concentration of PPI reached $10 \mathrm{mg} / \mathrm{mL}$. The scavenging activities of PPI on superoxide anion are presented in Figure 3C. The superoxide radical scavenging activities of PPI were concentration-dependent when the mass concentration of PPI was $1-8 \mathrm{mg} / \mathrm{mL}$ and the maximum clearance rate was $42.69 \%$. On the other hand, super-oxide-radical scavenging activities of PPI were decreased when the mass concentration of PPI was $10 \mathrm{mg} / \mathrm{mL}$. After combining with iron ions, PPI enhanced the ABTS scavenging activity much more than PSPF, but there was no significant change in ferrous ion and superoxide anion scavenging activity.

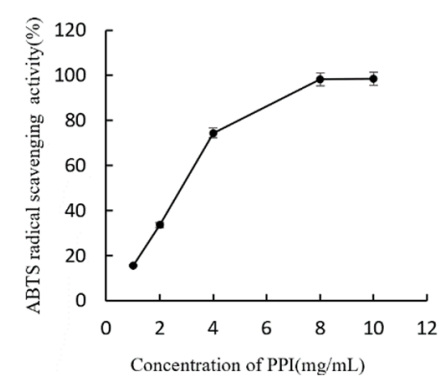

(A)

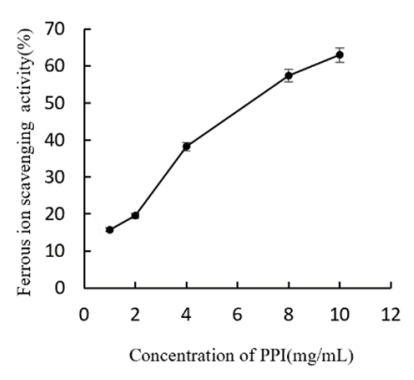

(B)

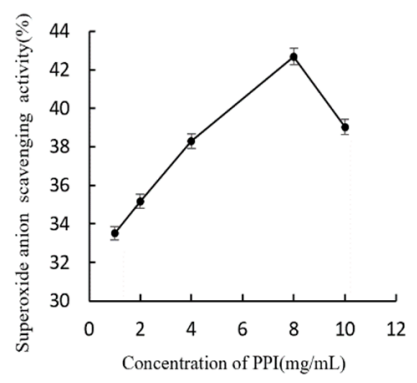

(C)

Figure 3. Antioxidant activity of PPI (A). Scavenging effects of PPI on ABTS radical. (B). Scavenging effects of PPI on ferrous ion scavenging. (C). Scavenging effects of PPI on superoxide anions.

\subsection{Effect of PPI on Cell Viability and Cell Morphology}

As shown in Figure 4A,B, the viability of Skov3 cells was significantly decreased after $24 \mathrm{~h}$ of exposure to PPI. Cell viability was affected in a dose-dependent manner, with the viability of Skov3 cells decreasing significantly as concentrations increased from 100 to $400 \mu \mathrm{g} / \mathrm{mL}$ PPI ( $p<0.05$; Figure 4B). Compared with PSPF, PPI has weaker inhibitory activity on cancer cell proliferation. The viability of human ovarian cancer cells decreased significantly exposure to 100 and $200 \mu \mathrm{g} / \mathrm{mL}$ PSPF [12].

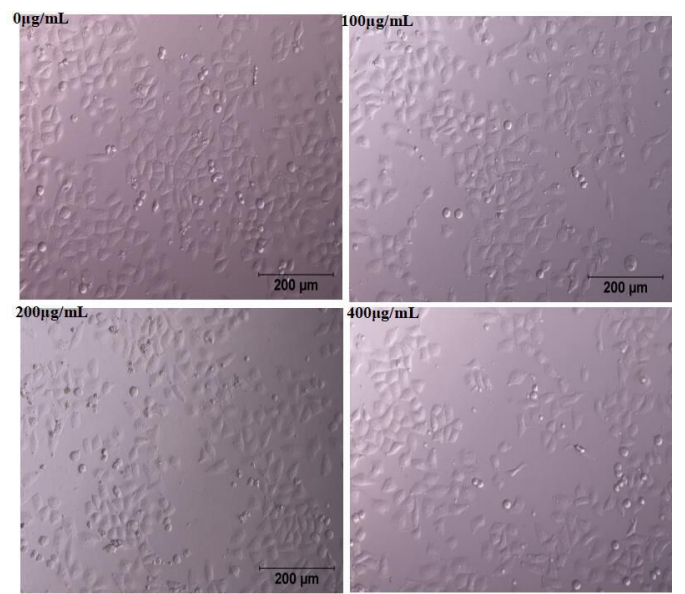

(A)

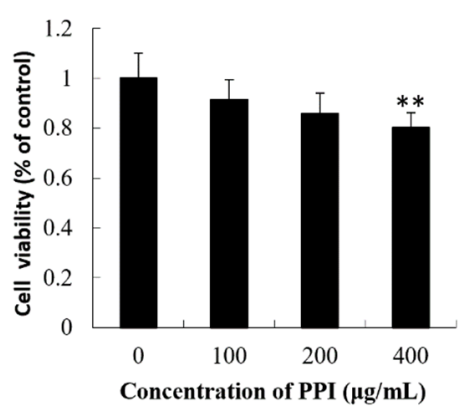

(B)

Figure 4. Cont. 


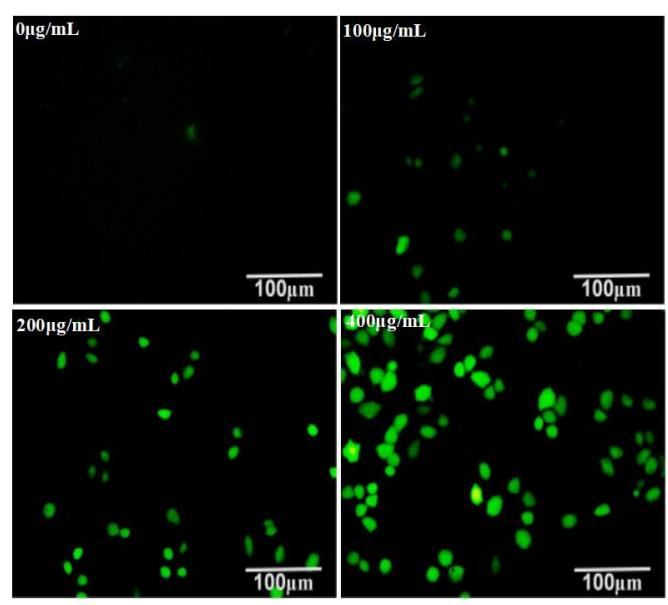

(C)

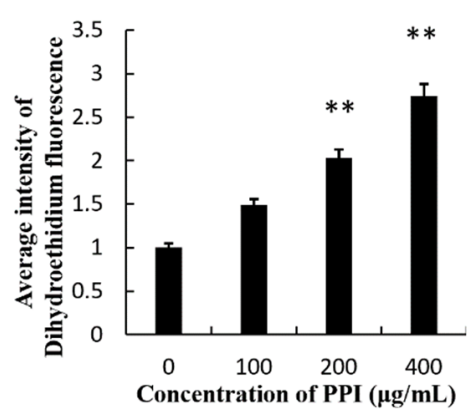

(D)

Figure 4. Effects of PPI on cell viability and evaluation of ROS level. (A). Phase contrast microscopy showing the morphology of Skov3 cells after PPI treatment for $24 \mathrm{~h}$. Scale bars $=200 \mu \mathrm{m}$. (B). Data for Skov3 cells. (C). Intracellular ROS levels were measured with fluorescence imaging using the DCFH-DA probe in cells cultured in the presence of PPI (0, 100, 200 and $400 \mu \mathrm{g} / \mathrm{mL}$ ) for $24 \mathrm{~h}$. Scale bars $=100 \mu \mathrm{m}$. (D). The average intensity of fluorescence in Skov3 cells. Data are expressed as mean \pm SD of three independent experiments performed in triplicate. ${ }^{* *} p<0.01$.

\subsection{PPI Increased Levels of Reactive Oxygen Species}

Studies have shown that ROS are closely related to apoptosis, as increasing the ROS level leads to a decrease in the level of cellular antioxidants, resulting in overall oxidative damage to cellular components $[24,25]$. ROS was detected using a fluorescent DCFH-DA probe. As shown in Figure 4C,D, the results indicate that the intercellular ROS induced by PPI in Skov3 cells was upregulated in a dose-dependent manner. Simultaneously, the results show that PPI was responsible for cell death and enhanced ROS production.

\subsection{Loss of Mitochondrial Membrane Potential ( $\Delta \psi m)$ and Apoptosis Induction}

The decline in $\Delta \Psi \mathrm{m}$ is an early marker of apoptosis. Cells have been shown to enter an irreversible apoptosis process if $\Delta \Psi \mathrm{m}$ is lost. JC-1, the ideal fluorescent probe for $\Delta \Psi \mathrm{m}$ detection, can easily be detected by the transition from red to green fluorescence [26,27]. The intensity of JC-1 was significantly decreased $(p<0.01)$ in the groups treated with PPI in a dose-dependent manner (Figure 5A,B). DNA degradation in the early stage of apoptosis was evaluated using the TUNEL assay [28]. Compared with the control group, TUNEL-positive cells and fluorescence intensity were high in the groups treated with higher concentrations of PPI (Figure 5C,D), indicating more pronounced apoptosis. Furthermore, the expression of proteins related to apoptosis were detected by Western blot analysis (see Section 2.9). The expression of Bax protein was significantly up-regulated while Bcl-2 was significantly down-regulated in PPI-treated Skov3 cells. Additionally, the expression of $\gamma-\mathrm{H} 2 \mathrm{AX}$ and RAD51, which were detected by immunofluorescence, were also significantly up-regulated (Figure 6). Compared with PSPF, PPI has weaker ability to induce cell apoptosis [12]. 


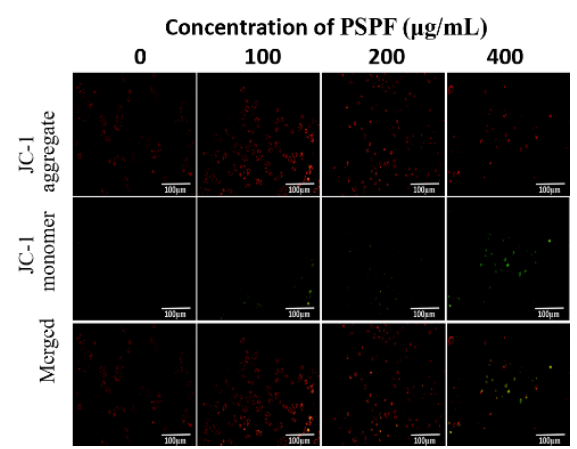

(A)

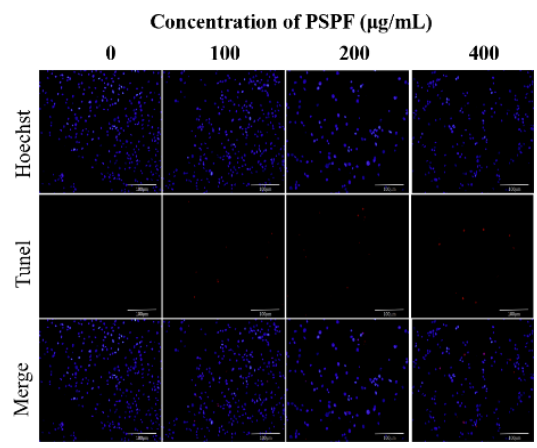

(C)

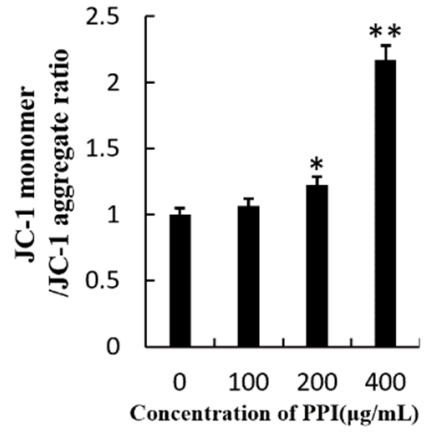

(B)

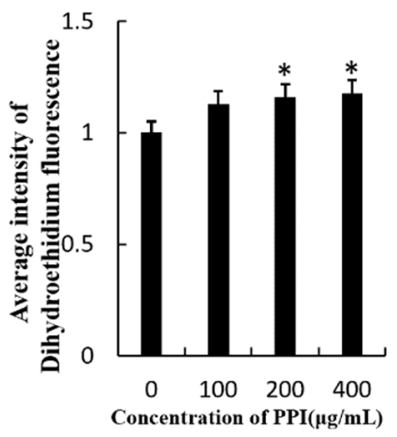

(D)

Figure 5. Loss of mitochondrial membrane potential $(\Delta \psi \mathrm{m})$ and TUNEL assay. (A). The $\Delta \psi \mathrm{m}$ was evaluated using JC-1 in treated cells. Red fluorescence indicates JC-1 aggregates within mitochondria in healthy cells, whereas green fluorescence indicates JC-1 monomers in the cytoplasm and loss of $\Delta \psi \mathrm{m}$. Scale bars $=100 \mu \mathrm{m}$. (B). Ratio of JC- 1 monomers to JC- 1 aggregates. (C). TUNEL assay in treated cells, scale bars $=100 \mu \mathrm{m}$. (D). Average intensity of TUNEL fluorescence in Skov3 cells. ${ }^{*} p<0.05,{ }^{* *} p<0.01$.

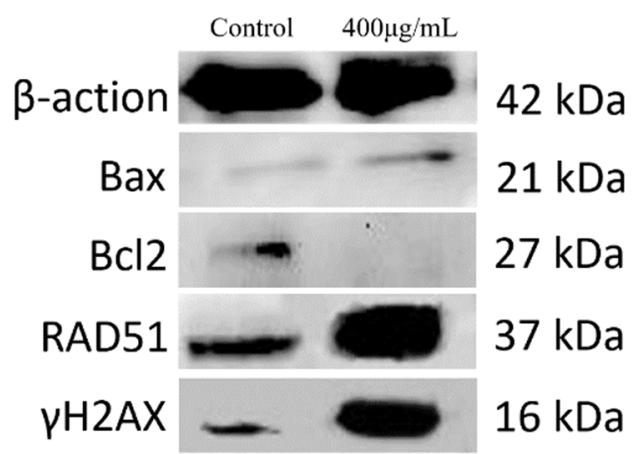

Figure 6. Western blotting. Bax, Bcl2, RAD51, $\gamma \mathrm{H} 2 \mathrm{AX}$ and p53 expression in Skov3 cells. Cells were treated with PPI at $400 \mu \mathrm{g} / \mathrm{mL}$ for $24 \mathrm{~h}$.

\subsection{PPI Induces Nuclear DNA Breakage}

Apoptosis is always accompanied by DNA damage. $\gamma$-H2AX and Rad51, both markers of DNA damage, play major roles in the repair process after DNA damage $[29,30]$. Levels of phosphorylated $\gamma-\mathrm{H} 2 \mathrm{AX}$ in cells exposed with PPI for $24 \mathrm{~h}$ were measured using immunofluorescent images (Figure 7A). Green fluorescence, which represents $\gamma$ H2AX, was remarkably enhanced in PPI-treated samples in a dose-dependent manner (Figure $7 \mathrm{~B}, p<0.01$ ). The presence of DNA damage was further confirmed by RAD51 staining (Figure 7C,D). We further analysed their expression using WB. The expression levels of $\gamma$-H2AX and RAD51 all were up-regulated in the $400 \mu \mathrm{g} / \mathrm{mL}$ PPI treatment group compared to the control group (Figure 6). 


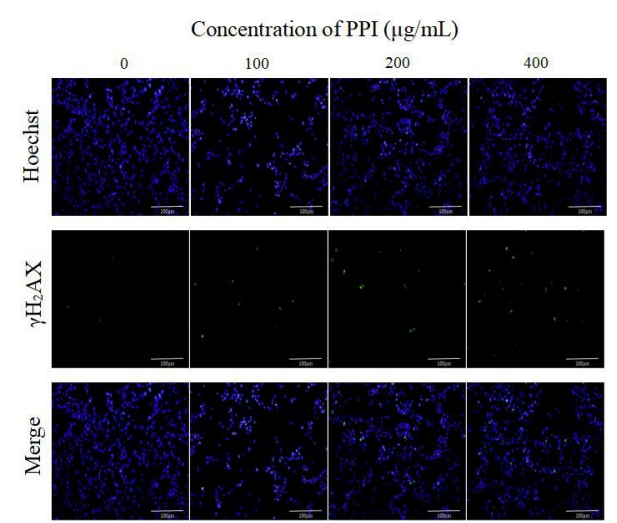

(A)

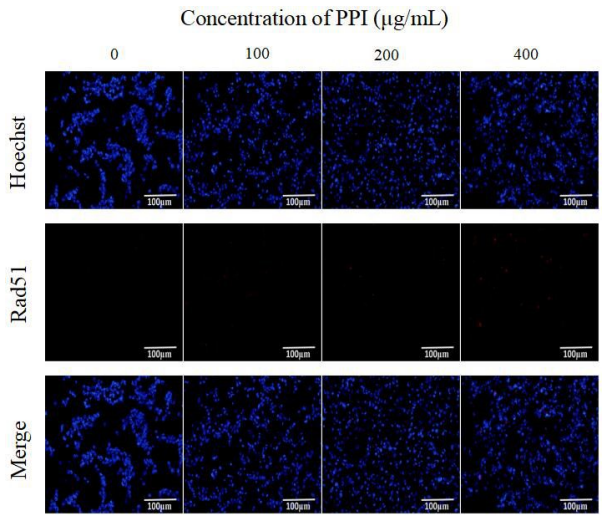

(C)

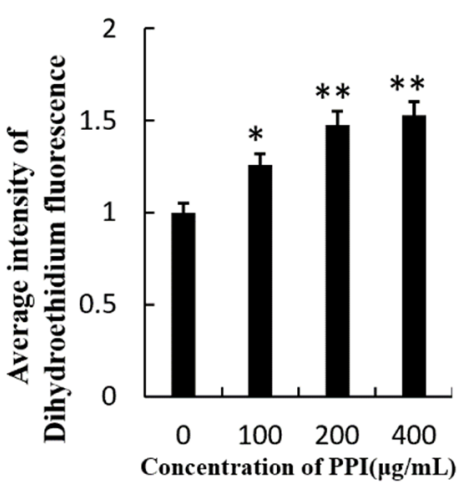

(B)

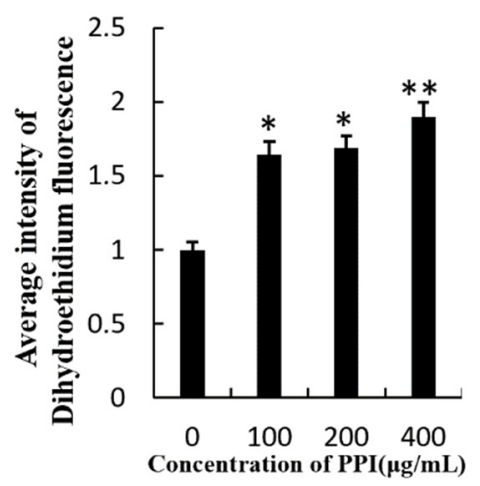

(D)

Figure 7. Nuclear DNA damage in Skov3 cells after CPPI treatment using immunocytofluorescence with $\gamma$-H2AX and Rad51 antibody. (A). Immunocytofluorescence with $\gamma-\mathrm{H} 2 \mathrm{AX}$ in treated cells. (B). Average intensity of green fluorescence in Skov3 cells. (C) Immunocytofluorescence with Rad51 in treated cells. (D). Average intensity of red fluorescence in Skov3 cells. Scale bars $=100 \mu \mathrm{m} .{ }^{*} p<0.05,{ }^{* *} p<0.01$.

\subsection{PPI Affected Gene Expression in Skov3 Cells}

In order to reveal the influence of PPI exposure on gene expression in Skov3 cell, Skov3 cell mRNA was examined by high-throughput sequencing. As shown in Figure 8A, a total of 29,078 genes were detected. There were 873 genes which were significantly different between control and PPI-treated groups. A total of 455 genes were significantly upregulated and 418 were down-regulated after PPI treatment. The scatter plot is presented as a $\log 2$ of fold change of signal intensity and blue spots represent genes expressed at similar levels; the up-regulated genes in the PPI-treated group are marked in red, and the down-regulated genes are marked in green. The hierarchical clustering analyses of the 863 differentially-expressed genes (DEGs) is shown in Figure 8B. Sterol biosynthetic process, secondary alcohol biosynthesis process and sterol metabolic process were the mainly enriched DEGs in BP; the DEGs in CC were related to the preribosome, 90s preribosome and membrane region, and snoRNA binding and coenzyme binding were significant DEGs in MF between the control and PPI-treated group (Figure 8C,D). Through KEGG analysis, steroid biosynthesis, carbon metabolism and terpenoid backbone biosynthesis were the most significantly altered signalling pathways between the control and treated groups (Figure 8E,F). PPI also causes cell ferroptosis, a new cell death mode discovered in recent years (Figure 8E,F). 


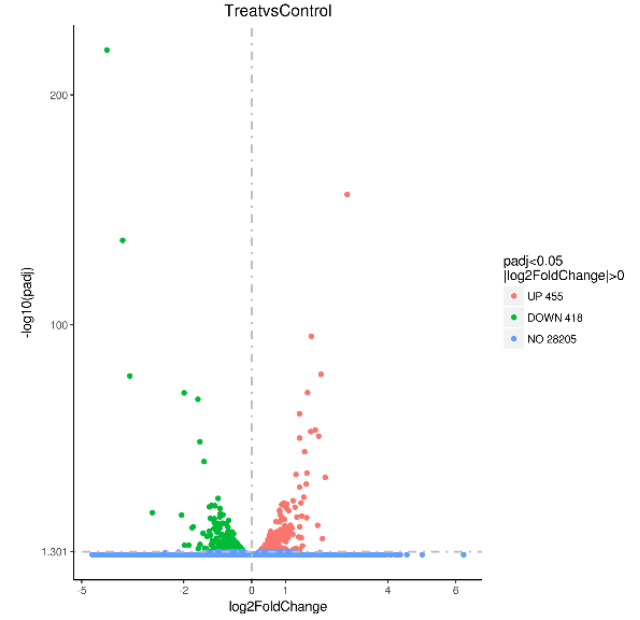

(A)

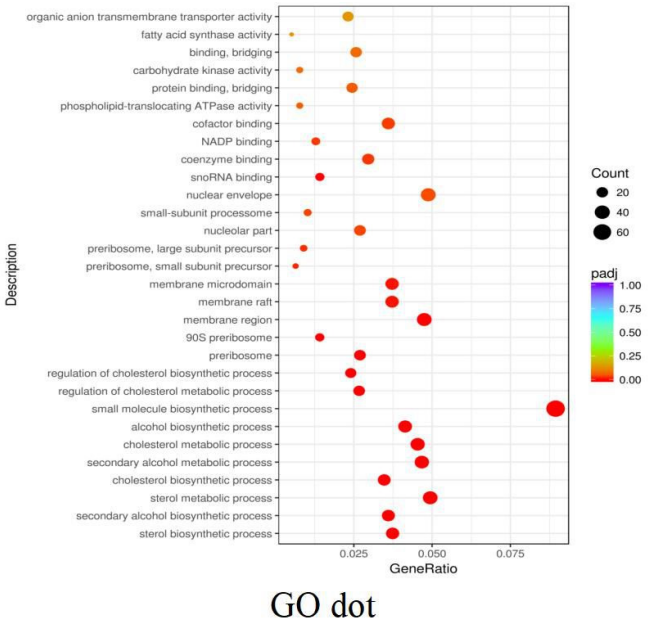

(C)

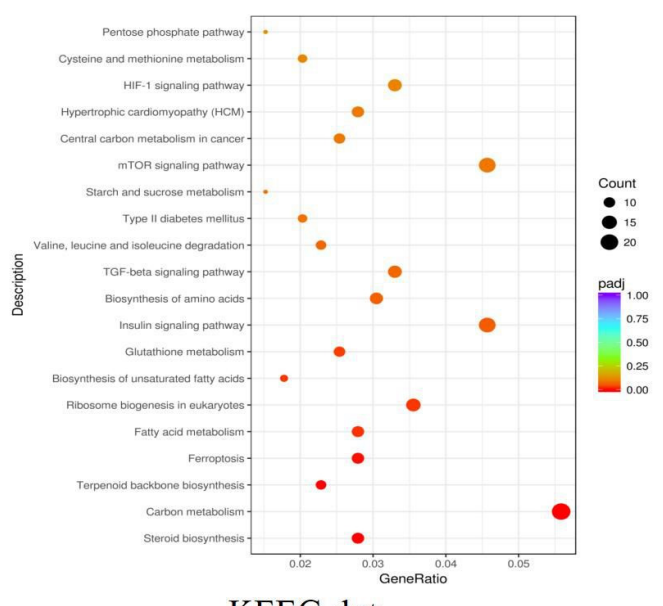

KEEG dot

(E)

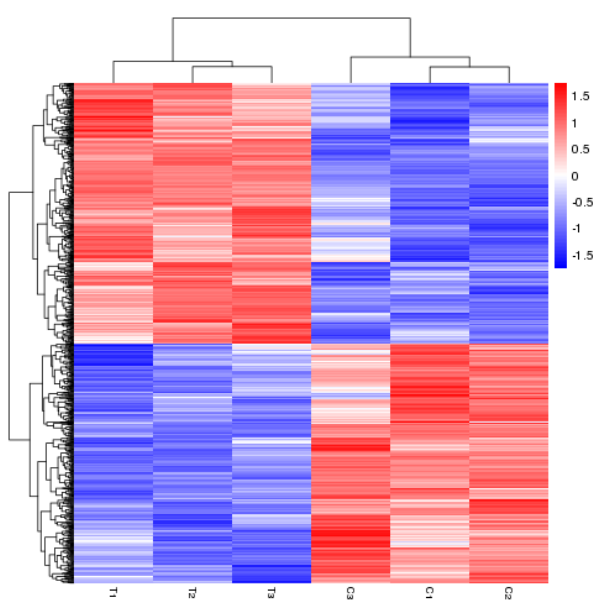

(B)

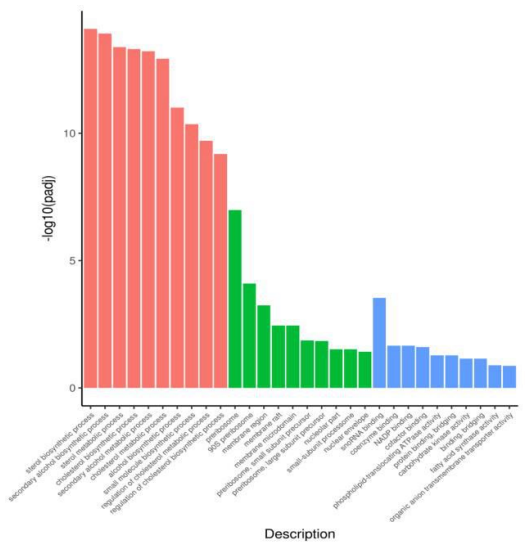

GO bar

(D)

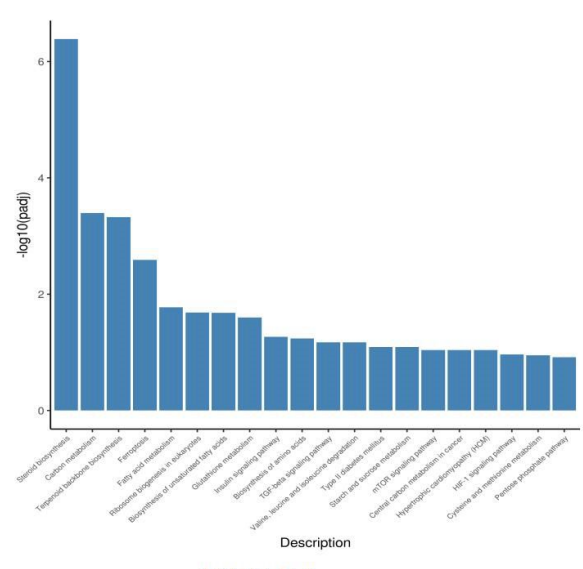

KEEG bar

(F)

Figure 8. Gene expression in PPI-treated cells. Scatter plot of PPJ-treated Skov3 cell gene expression profiling. (A) The 455 up-regulated genes and 418 down-regulated genes in the treated group are plotted in green and red, respectively. (B) Hierarchical clustering analyses of the differentially expressed genes in two replicates of the two groups. (C) Dot plots of overrepresented gene ontology (GO) terms in molecular function (MF), biological process (BP) and cellular component (CC) categories. (D) Bar plots of overrepresented GO terms in MF, BP and CC categories. (E) Dot plots of Kyoto Encyclopaedia of Genes and Genomes (KEGG) terms. (F) Bar plots of KEGG terms. Top ten significant terms are shown in each category $(p<0.05)$. 


\section{Conclusions}

In this study, PPI was synthesised and studied in detail. The synthesis of PPI was successfully optimised using RSM. The optimal conditions that achieved maximum complex yield were a reaction temperature of $70^{\circ} \mathrm{C}, \mathrm{pH} 8.9$ and a catalyst to polysaccharide ratio of 0.5 . Under the optimal conditions, the PPI produced was a reddish-brown powder with an iron content of PPIC that reached $30.76 \%$, which suggests that the model was satisfactory and accurate. In addition, the antioxidant study found that PPIs have a clear role in scavenging superoxide radicals, metal ions and ABTS radicals. The results indicate that PPI had antioxidant activities in the in vitro assays. Additionally, we also verified that PPI could induce significant cytotoxicity, as evidenced by an increase in intracellular ROS, mitochondrial membrane potential disruption and consequent DNA damage. Moreover, PPI exposure significantly altered the cancer-related gene expression pattern of Skov3 cells in vitro, which suggests that PPI could be a potential drug for anticancer therapy.

\section{Materials and Methods}

\subsection{Drugs and Reagents}

Pyracantha fortuneana polysaccharide (PSPF) were extracted and purified in our laboratory [12], sodium citrate tribasic, 2,20-azino-bis (3-ethylbenzthiazoline-6-sulfonic) acid (ABTS) was provided by Sigma (St. Louis, MO, USA). All other chemicals and reagents were purchased locally and were of analytical grade.

\subsection{Preparation of Polysaccharide}

Pyracantha fortuneana polysaccharide (PSPF) was extracted with water and alcohol precipitation under the following conditions: extraction time of $2.1 \mathrm{~h}, 61.5^{\circ} \mathrm{C}$, ratio of water to raw material $=36.3$ [12]. D101 macroporous adsorption resin was used for pigment removal with protein removed by the Sevage method. The resultant polysaccharide was collected, concentrated, dialysed and lyophilised for purification.

\subsection{Single Factor Experimental Data Analysis}

Based on a literature review of the synthesis process of polysaccharide iron, the main factors affecting polysaccharide iron are as follows: citric acid, the ratio of catalyst to polysaccharide, temperature, $\mathrm{pH}$ and reaction time [31]. In this study, $\mathrm{pH}$, temperature and the ratio of catalyst to polysaccharide were selected as three independent variables. As shown in Table 3, $\mathrm{pH}=8$, temperature $=60{ }^{\circ} \mathrm{C}$ and the ratio of catalyst to polysaccharide $=1.25$ were each at their optimal values.

Table 3. Levels and code of extraction variables used in Box-Behnken design.

\begin{tabular}{ccccc}
\hline \multirow{2}{*}{ Variable } & Symbols & \multicolumn{3}{c}{ Coded Levels } \\
\cline { 2 - 5 } & Coded & $-\mathbf{1}$ & $\mathbf{0}$ & $\mathbf{1}$ \\
\hline $\mathrm{pH}$ & $\mathrm{X}_{1}$ & 7 & 8 & 9 \\
Reaction temperature & $\mathrm{X}_{2}$ & 50 & 60 & 70 \\
Sodium Citrate & $\mathrm{X}_{3}$ & 0.5 & 1.25 & 2 \\
tribasic/Polysaccharide ratio & & & \\
\hline
\end{tabular}

\subsection{Synthesis of Pyracantha Polysaccharide-Iron(III) Complex (PPI)}

PPI was synthesised chemically. Other methods of PPI synthesis that have previously been documented include the ammonium sulphate method and the composite membrane method; Tang and Liu have prepared the polysaccharide iron complex using a chemical synthesis method [32].

\subsection{Response Surface Design}

In this experiment, the iron content of PPI was used as an evaluation index. The PPI at points based on the experimental design are shown in Table 2. The whole design consisted 
of 17 experimental points carried out at random. The best fitting model was the result of RSM as determined via regression using Design Expert software (v.8.0.6.1 trial, Stat-Ease Inc., Minneapolis, MN, USA). At the bottom of Table 1, the fitted quadratic polynomial equation is given as follows: $Y=0.52+0.0 .015 \mathrm{X}_{1}+0.026 \mathrm{X}_{2}--0.031 \mathrm{X}_{3}+0.025 \mathrm{X}_{1} \mathrm{X}_{2}-$ $2.35^{*} 10^{-3} \mathrm{X}_{1} \mathrm{X}_{3}-0.026 \mathrm{X}_{2} \mathrm{X}_{3}-0.022 \mathrm{X}_{1}^{2}-0.017 \mathrm{X}_{2}^{2}+9.1^{*} 10^{-4} \mathrm{X}_{3}^{2}$.

\subsection{Determination of PPI}

\subsubsection{Establishment of Standard Curve for Iron}

The two valent iron standard solution configuration is as follows: a standard iron solution was prepared by dissolving $0.7025 \mathrm{~g}$ of $\left(\mathrm{NH}_{4}\right) \mathrm{Fe}\left(\mathrm{SO}_{4}\right)_{2} \cdot \mathrm{H}_{2} \mathrm{O}$ in $1000 \mathrm{~mL}$ of distilled water with the addition of $2 \mathrm{~mL}$ of hydrochloric acid iron. Then, $0,1,2,3,4,5,6$ and $7 \mathrm{~mL}$ of iron standard solution was added to $1.75 \mathrm{~mL}$ of ascorbic acid and $2.5 \mathrm{~mL}$ of phenanthroline. After $10 \mathrm{~min}$, the UV absorbance of sample was assessed at $510 \mathrm{~nm}$. Finally, the corresponding standard curve was obtained. The calibration curve was $y=0.0982 x+0.0041, R^{2}=0.9999$.

\subsubsection{Determination of the Iron Content in PPI}

The iron content was measured using the phenanthroline colorimetric method [33]. For this, $0.05 \mathrm{~g}$ of PPI was dissolved in $50 \mathrm{~mL}$ of water, then $1.0 \mathrm{~mL}$ of the sample was mixed with $2.5 \mathrm{~mL}$ of $10 \%$ ascorbic acid solution and $5 \mathrm{~mL}$ of $0.1 \%$ o-phenanthroline solution. Finally, the solution was adjusted to $50 \mathrm{~mL}$ with water. After $3 \mathrm{~h}$, the UV absorbance of the sample was assessed at $510 \mathrm{~nm}$. The iron content of PPI was calculated using the calibration curve.

\subsubsection{Experimental Design}

RSM is a mathematical and statistical technique to optimise the available parameters through the least number of experiments and to analyse the interaction between these parameters [34,35]. In this study, RSM was adopted to optimise the process conditions for PPI production. The three-level Box-Behnken design (BBD) was used to evaluate three independent variables on the basis of single factor experiments: $\mathrm{pH}\left(\mathrm{X}_{1}\right)$, temperature $\left(\mathrm{X}_{2}\right)$ and the ratio of catalyst to PSPF $\left(\mathrm{X}_{3}\right)$. The iron content of PPI was selected as the response. The variables and their respective levels are presented in Table 1.

ANOVA was used for the statistical analysis. $p$-values less than 0.05 were considered statistically significant. ANOVA, regression analysis and the response surface rendering method were used to fit the quadratic polynomial equation of all response variables in order to obtain the optimum conditions for complex formation.

\subsubsection{Antioxidant Activities of PPI}

The antioxidant activities of PPI were assessed based on previously established methods [36-39]. For this, 1, 2, 4, 8 and $10 \mathrm{mg} / \mathrm{mL}$ PPI was prepared in water. The scavenging ability for pyrogallol autoxidation was calculated: inhibition rate $(\%)=\left(1-\left(\mathrm{A}_{1}-\mathrm{A}_{2}\right) / \mathrm{A}_{0}\right)$ $\times 100 \%$, where $A_{0}$ is the absorbance of the control (water instead of sample), $A_{1}$ is the absorbance of the sample and $A_{2}$ is the absorbance of the sample with anhydrous ethanol instead of pyrogallol.

\subsection{Characterisation of PPI}

\subsubsection{UV and FTIR Analysis}

PSPF and PPI powder were dissolved in $50 \mathrm{~mL}$ of water. The absorbance was measured from 200 to $450 \mathrm{~nm}$ using an ultraviolet spectrum scan. Absorptions of PSPF and PPI were identified by the FTIR spectrum. Approximately $2 \mathrm{mg}$ of PSPF and PPI powder were weighed and mixed with $\mathrm{KBr}$ powder, ground and pressed for FTIR measurements through spectrometry (PerkinElmer, Spectrum 400, Waltham, MA, USA). 


\subsubsection{SEM Analysis}

The surface morphology of PPI and PSPF were analysed by scanning electron microscopy (Hitachi, Tokyo, Japan). With the help of double-sided tape, the sample was placed on a brass stub and observed after coating with gold in a vacuum by a sputter coater.

\subsubsection{Circular Dichroism (CD) Analysis}

The CD spectra of PSPF and PPI solutions $(1.0 \mathrm{mg} / \mathrm{mL})$ were measured on a Chirascan V100 CD (Applied Photophysics, Leatherhead, UK) spectropolarimeter at $25^{\circ} \mathrm{C}$. Each CD spectrum was the accumulation of three scans at $100 \mathrm{~nm} / \mathrm{min}$ with a $1 \mathrm{~nm}$ slit width and a time constant of $1 \mathrm{~s}$. Data were collected from 185 to $300 \mathrm{~nm}$ at $1 \mathrm{~nm}$ intervals.

\subsubsection{Structural Characteristics of PSPF and PPI}

$X$-ray diffraction (XRD) analysis was performed with an X-ray diffractometer (D8ADVANCE, Bruker, Karlsruhe, Germany). The X-ray diffractometer was operated at $40 \mathrm{kV}$ and $30 \mathrm{~mA}$ produced with a $\mathrm{Cu}-\mathrm{k} \alpha$ radiation. The $\mathrm{XRD}$ patterns were recorded over $5-90^{\circ}$ ( $\theta$ being the angle of diffraction) at a rate of $4^{\circ} / \mathrm{min}$.

\subsubsection{Thermogravimetric Analysis (TGA)}

A simultaneous thermal analyser (STA449F3, Netzsch Corporation, Selb, Germany) was applied to determine the thermal stability of PPI. Approximately $10 \mathrm{mg}$ of PPI powder was placed in a platinum crucible and heated from 30 to $650{ }^{\circ} \mathrm{C}$ at a rate of $10^{\circ} \mathrm{C} / \mathrm{min}$ in a nitrogen atmosphere with a flow rate of $50 \mathrm{~mL} / \mathrm{min}$.

\subsubsection{Nuclear Magnetic Resonance (NMR) Analysis}

For NMR measurements, PPI and PSPF powder were completely dissolved in $0.5 \mathrm{~mL}$ of dimethyl-d6 sulfoxide (D-DMSO) and transferred into an NMR tube. The ${ }^{1} \mathrm{H}$ spectra experiments were recorded at room temperature at $500 \mathrm{MHz}$ on a spectrometer (AVIII500, Bruker, Fällanden, Switzerland).

\subsubsection{Cytotoxicity of PPI Assay and ROS Assay}

Skov3 (human ovarian carcinoma cells) were cultured in DMEM/F12 medium + FBS $(10 \%)$ and antibiotics $(100 \mathrm{U} / \mathrm{mL}$ penicillin together with $100 \mu \mathrm{g} / \mathrm{mL}$ streptomycin) in a $5 \%$ $\mathrm{CO}_{2}$ atmosphere at $37^{\circ} \mathrm{C}$ in humidified incubator. Different concentrations of PPI $(0,100$, $200,400 \mu \mathrm{g} / \mathrm{mL}$ ) were used to treat cells for $24 \mathrm{~h}$, and the MTT assay was used to evaluate the cytotoxicity of PPI [40]. The S0033 detection kit (Beyotime, Haimen, Jiangsu, China) was used to measure the intracellular ROS levels in accordance with this method.

\subsubsection{Jc-1 Assays, TUNEL Assay and Immunohistochemistry}

The JC-1 Mitochondrial Membrane Potential Kit (Beyotime, Shanghai, China) and TUNEL BrightRed Apoptosis Detection Kit (Vazyme, Piscataway, NJ, USA) were used to detected the quantity of JC-1 and apoptotic cells, respectively. Cell that were treated with PPI for $24 \mathrm{~h}$ were subjected to both the Jc-1 assay and TUNEL assay. Primary antibodies against anti- $\gamma \mathrm{H} 2 \mathrm{AX}$ and anti-Rad51 were used for immunohistochemistry based on published methods [12].

\subsubsection{Western Blot Analysis}

Cells were treated with $400 \mu \mathrm{g} / \mathrm{mL}$ PPI for $12 \mathrm{~h}$ in order to produce cell pellets for western blot analysis [41]. The following primary antibodies were used: anti-Rad51 (Abcam ab88572, London, UK), anti- $\gamma \mathrm{H} 2 \mathrm{AX}$ (Abcam ab26350, London, UK), anti-Bcl2 (ImmunoWay YT0470, Suzhou Jiangsu, China), anti-BAX (Cell Signaling Technology, \#2772, Boston, MA, USA) and $\beta$-action (Abcam ab8227, London, UK). 


\subsubsection{Bioinformatics Analysis of the mRNA Expression Profile}

RNA extraction and RNA expression profiling were performed based on pre-existing methods [42]. GenePix 4.1 software (Molecular Devices, Sunnyvale, CA, USA) was used to analyse to microarray signal intensity of each spot. Three replicates in one group were used.

The expressions of mRNAs with log2 $\mid$ fold change $\mid>1$ (absolute $\mid$ fold change $\mid>2$ ) and $p<0.05$ were defined as differentially expressed mRNAs. Hierarchical clustering analysis combined with a heatmap was applied to evaluate the three samples within each group and the differences between the two groups. An average linkage hierarchical clustering was generated using the $\mathrm{R}$ program in the heatmap.2 package, a function of g-plots package that is used for hierarchical clustering. Gene ontology analysis was performed using DAVID, a database for gene functional annotation.

\subsubsection{Statistical Method}

The differences between mean values were statistically tested using Student's $t$ test or one-way ANOVA followed by the Tukey test for multiple comparisons. Comparisons were considered significant at $p<0.05$ and $p<0.01$ (asterisk).

Author Contributions: X.-F.Z. designed the study. W.-F.L., H.-H.M., S.Y. and X.-F.Z. collected data. All authors have read and agreed to the published version of the manuscript.

Funding: This work was supported by the High level talents research fund project of Qingdao Agricultural University in China (1120043) to X.-F.Z.

Institutional Review Board Statement: Not applicable.

Informed Consent Statement: Not applicable.

Data Availability Statement: The data presented in this study are available in the article.

Conflicts of Interest: The authors declare no conflict of interest.

Sample Availability: Samples of the compounds are not available from the authors.

\section{References}

1. Wang, X.H.; Bai, H.Q.; Wulangerile. Progress in the Studies of Polysaccharide Metal Complex. J. Inn. Mong. Univ. Natl. 2014, 29, 516-519. [CrossRef]

2. Danielson, B.G. Structure, chemistry, and pharmacokinetics of intravenous iron agents. J. Am. Soc. Nephrol. 2004, 15, 93-98.

3. Eichbaum, Q.; Foran, S.; Dzik, S. Is iron gluconate really safer than iron dextran? Blood 2003, 101, 3756. [CrossRef]

4. Johnson, C.A.; Rosowski, E.; Zimmerman, S.W. A prospective open-label study evaluating the efficacy and adverse reactions of the use of Niferex-150 in ESRD patients receiving EPOGEN. Adv. Perit. Dial. Conf. Perit. Dial. 1992, 8, $444-447$.

5. Floyd, R.A.; Lewis, C.A. Hydroxyl free radical formation from hydrogen peroxide by ferrous iron-nucleotide complexes. Biochemistry 1983, 22, 2645-2649. [CrossRef] [PubMed]

6. Oates, P.S.; Morgan, E.H. Defective iron uptake by the duodenum of Belgrade rats fed diets of different iron contents. Am. J. Physiol. Liver Physiol. 1996, 270, G826-G832. [CrossRef] [PubMed]

7. Kudasheva, D.S.; Lai, J.; Ulman, A.; Cowman, M.K. Structure of carbohydrate-bound polynuclear iron oxyhydroxide nanoparticles in parenteral formulations. J. Inorg. Biochem. 2004, 98, 1757-1769. [CrossRef] [PubMed]

8. Chen, Z.W.; Zhang, Q.; Wang, S.H.; Shi, L. Study on the synthesis technique of angelica polysaccharides iron complex by orthogonal test. Med. J. Defending Forces Southwest China 2003, 13, 374-376. [CrossRef]

9. He, R.X.; Gao, W.H.; Zhu, S.M. Preparation and characters of soluble soybean polysaccharide-iron (III) complex. Sci. Technol. Food Ind. 2012, 2, 326-330, doiorg/101155/2019/6416941.

10. Wu, G.J.; Li, Y.P.; Hu, L.; Chen, Z.Q.; Hong, L.M. Synthesis of Portulace oleracea L. polysaccharide iron complex and its physicalchemical properties. Food Sci. Technol. 2012, 37, 250-252. [CrossRef]

11. Li, S.J. Study on Chemical and Antioxidation of Fruit of Pyracantha Resources; Huazhong University of Science and Technology: Wuhan, China, 2011.

12. Yao, Y.-L.; Shu, C.; Feng, G.; Wang, Q.; Yan, Y.-Y.; Yi, Y.; Wang, H.-X.; Zhang, X.-F.; Wang, L.-M. Polysaccharides from Pyracantha fortuneana and its biological activity. Int. J. Biol. Macromol. 2020, 150, 1162-1174. [CrossRef]

13. Yang, T.; Zhang, S.; Wang, R.; Li, D.; Hu, Y.; Nie, J.; Zhao, X.; Wang, Q.; Chen, Y.; Zheng, Y.; et al. Polysaccharides from Rhizoma Panacis Majoris and its anti-oxidant activity. Int. J. Biol. Macromol. 2016, 86, 756-763. [CrossRef] [PubMed]

14. Zhao, Z.-Y.; Zhang, Q.; Shu-Lin, L.; Dong, L.-L.; Liu, S.-L. Optimization of ultrasound extraction of Alisma orientalis polysaccharides by response surface methodology and their antioxidant activities. Carbohydr. Polym. 2015, 119, 101-109. [CrossRef] 
15. Mehmood, T.; Ahmed, A.; Ahmad, A.; Ahmad, M.S.; Sandhu, M.A. Optimization of mixed surfactants-based $\beta$-carotene nanoemulsions using response surface methodology: An ultrasonic homogenization approach. Food Chem. 2018, 253, 179-184. [CrossRef] [PubMed]

16. Celebi, N.; Yildiz, N.; Demir, A.S.; Çalımlı, A.; Calimli, A.; Yıldız, N. Optimization of benzoin synthesis in supercritical carbon dioxide by response surface methodology (RSM). J. Supercrit. Fluids 2008, 47, 227-232. [CrossRef]

17. Chang, H.Y.; Ho, Y.L.; Sheu, M.J.; Lin, Y.H.; Tseng, M.C.; Wu, S.H.; Huang, G.J.; Chang, Y.S. Antioxidant and free radical scavenging activities of Phellinus merrillii extracts. Bot. Stud. 2007, 48, 407-417.

18. Pitarresi, G.; Tripodo, G.; Cavallaro, G.; Palumbo, F.S.; Giammona, G. Inulin-iron complexes: A potential treatment of iron deficiency anaemia. Eur. J. Pharm. Biopharm. 2008, 68, 267-276. [CrossRef]

19. Marshall, P.; Rutherford, D. Physical investigations on colloidal iron-dextran complexes. J. Colloid Interface Sci. 1971, 37, 390-402. [CrossRef]

20. Park, J.; Chakrabarti, B. Optical characteristics of carboxyl group in relation to the circular dichroic properties and dissociation constants of glycosaminoglycans. Biochim. et Biophys. Acta (BBA)—Gen. Subj. 1978, 544, 667-675. [CrossRef]

21. Chi, Y.; Li, Y.; Zhang, G.; Gao, Y.; Ye, H.; Gao, J.; Wang, P. Effect of extraction techniques on properties of polysaccharides from Enteromorpha prolifera and their applicability in iron chelation. Carbohydr. Polym. 2018, 181, 616-623. [CrossRef]

22. Bertini, I.; Luchinat, C.; Parigi, G.; Pierattelli, R. NMR Spectroscopy of Paramagnetic Metalloproteins. ChemBioChem 2005, 6, 1536-1549. [CrossRef]

23. Kästele, X.; Sturm, C.; Klüfers, P. ${ }^{13} \mathrm{C}$ NMR spectroscopy as a tool for the in situ characterisation of iron-supplementing preparations. Eur. J. Pharm. Biopharm. 2014, 86, 469-477. [CrossRef]

24. Bai, D.-P.; Zhang, X.-F.; Zhang, G.-L.; Huang, Y.-F.; Gurunathan, S. Zinc oxide nanoparticles induce apoptosis and autophagy in human ovarian cancer cells. Int. J. Nanomed. 2017, 12, 6521-6535. [CrossRef]

25. Carmody, R.; Cotter, T. Signalling apoptosis: A radical approach. Redox Rep. 2001, 6, 77-90. [CrossRef]

26. Ishikawa, K.; Takenaga, K.; Akimoto, M.; Koshikawa, N.; Yamaguchi, A.; Imanishi, H.; Nakada, K.; Honma, Y.; Hayashi, J.-I. ROS-Generating Mitochondrial DNA Mutations Can Regulate Tumor Cell Metastasis. Science 2008, 320, 661-664. [CrossRef] [PubMed]

27. Turrens, J.F. Mitochondrial formation of reactive oxygen species. J. Physiol. 2003, 552, 335-344. [CrossRef] [PubMed]

28. Darzynkiewicz, Z.; Galkowski, D.; Zhao, H. Analysis of apoptosis by cytometry using TUNEL assay. Methods 2008, 44, 250-254. [CrossRef]

29. Redon, C.E.; Dickey, J.S.; Bonner, W.M.; Sedelnikova, O.A. $\gamma$-H2AX as a biomarker of DNA damage induced by ionizing radiation in human peripheral blood lymphocytes and artificial skin. Adv. Space Res. 2009, 43, 1171-1178. [CrossRef] [PubMed]

30. Rothkamm, K.; Horn, S. gamma-H2AX as protein biomarker for radiation exposure. Annali dell'Istituto Superiore di Sanità 2009, 45, 265-271.

31. He, D.; Yuan, X.; Lin, G.; Chen, W. Determination of iron ion in polysaccharide iron complex pellets. Chin. J. Hosp. Pharm. 2006, 26, 107-108. [CrossRef]

32. Tang, C.N. Research Progress of Polysaccharide-iron Complex(PIC). Anhui Chem. Ind. 2012, 38, 1-36. [CrossRef]

33. Saywell, L.G.; Cunningham, B.B. Determination of Iron: Colorimetric o-Phenanthroline Method. Ind. Eng. Chem. Anal. Ed. 1937, 9, 67-69. [CrossRef]

34. Azargohar, R.; Dalai, A. Production of activated carbon from Luscar char: Experimental and modeling studies. Microporous Mesoporous Mater. 2005, 85, 219-225. [CrossRef]

35. Adegoroye, A.; Wang, L.; Omotoso, O.; Xu, Z.; Masliyah, J. Characterization of organic-coated solids isolated from different oil sands. Can. J. Chem. Eng. 2010, 88, 462-470. [CrossRef]

36. Du, X.; Mu, H.; Zhou, S.; Zhang, Y.; Zhu, X. Chemical analysis and antioxidant activity of polysaccharides extracted from Inonotus obliquus sclerotia. Int. J. Biol. Macromol. 2013, 62, 691-696. [CrossRef] [PubMed]

37. Gao, C.; Wang, Y.; Wang, C.; Wang, Z. Antioxidant and immunological activity in vitro of polysaccharides from Gomphidius rutilus mycelium. Carbohydr. Polym. 2013, 92, 2187-2192. [CrossRef] [PubMed]

38. Hu, Y.; Sheng, Y.; Yu, M.; Li, K.; Ren, G.; Xu, X.; Qu, J. Antioxidant activity of Inonotus obliquus polysaccharide and its amelioration for chronic pancreatitis in mice. Int. J. Biol. Macromol. 2016, 87, 348-356. [CrossRef]

39. Ben Jeddou, K.; Chaari, F.; Maktouf, S.; Nouri-Ellouz, O.; Helbert, C.B.; Ghorbel, R.E. Structural, functional, and antioxidant properties of water-soluble polysaccharides from potatoes peels. Food Chem. 2016, 205, 97-105. [CrossRef]

40. Paździoch-Czochra, M.; Wideńska, A. Spectrofluorimetric determination of hydrogen peroxide scavenging activity. Anal. Chim. Acta 2002, 452, 177-184. [CrossRef]

41. Gurunathan, S.; Zhang, X.-F.; Choi, Y.-J.; Han, J.W.; Kim, E.; Park, J.H.; Kim, J.-H. Differential nanoreprotoxicity of silver nanoparticles in male somatic cells and spermatogonial stem cells. Int. J. Nanomed. 2015, 10, 1335-1357. [CrossRef] [PubMed]

42. Li, L.; Liu, J.-C.; Zhao, Y.; Lai, F.-N.; Yang, F.; Ge, W.; Dou, C.-L.; Shen, W.; Zhang, X.-F.; Chen, H. Impact of diethylhexyl phthalate on gene expression and development of mammary glands of pregnant mouse. Histochem. Cell Biol. 2015, 144, 389-402. [CrossRef] [PubMed] 